\title{
Synthesis of nanoporous carbons from mixtures of coal tar pitch and furfural and their application as electrode materials
}

\author{
N. Petrov', T. Budinova ${ }^{1 \#}$, B. Tsyntsarski ${ }^{1}$, B. Petrova ${ }^{1}$, C.O. Ania ${ }^{2}$, J.B. Parra $^{2}$ M. Mladenov ${ }^{3}$ P. \\ Tzvetkov $^{3}$ \\ ${ }^{1}$ Institute of Organic Chemistry, Bulgarian Academy of Sciences, Sofia 1113, Acad.G. Bonchev str., bl. 9, fax \\ (359-2) 7002 25, e-mail: goriva@orgchm.bas.bg, Bulgaria \\ ${ }^{2}$ Instituto Nacional del Carbón, CSIC, Apartado 73, 33080 Oviedo, Spain \\ ${ }^{3}$ Institute of Electrochemistry, Bulgarian Academy of Sciences, Sofia 1113, Acad. G. Bonchev str., bl.10 \\ \# - corresponding author
}

\begin{abstract}
:
Synthetic nanoporous carbons are prepared by polymerization of mixtures containing coal tar pitch and furfural in different proportions, followed by carbonization of obtained solid product and steam activation of the carbonizate. The chemical composition of the initial mixture significantly affects the physicochemical properties (surface area, pore structure, electro resistance and amount of oxygen containing groups on the surface) of the obtained materials. The incorporation if oxygen in the precursor mixture by means of furfural, has a strong influence in the synthetic route; rising the furfural content facilitates the formation of a solid product characterized by a large oxygen content. Moreover, the solid product is more reactive towards activation as the furfural content increases, giving rise to nanoporous carbons with large surface areas and unique chemical features (high density of oxygen functionalities of basic nature). These nanoporous carbons have been investigated as electrodes in electrochemical applications.
\end{abstract}

\section{Introduction}


To date, carbon materials play a major role in many science and engineering fields both as structural and functional materials. The majority of their applications derive from the flexible coordination chemistry of carbon atoms (allowing an infinite possibility of 3-dimensional structures) and their ability to bind other heteroatoms. For instance, surface chemistry of carbon materials may define the self-organization of the material, or its chemical stability and reactivity in adsorptive and catalytic processes, among most important applications [1]. Driven by the need for highly featured materials in many multidisciplinary areas, recent advances on synthetic routes have enabled to develop materials with unforeseen control over structure and properties that offer unexpected opportunities [1-3] for porous materials. Indeed, in the last decade most research on the design and processing of novel porous carbon materials has aimed to control the size, shape and uniformity of the porous void, contributing to developments in areas beyond the traditional use of porous materials as catalysts and adsorbents [4]. Besides porosity, surface chemistry of materials provides an unlimited, imaginative and simple tool to face newly arisen environmental challenges.

Most common synthetic procedures to prepare porous carbon materials are based on: traditional chemical and physical activation (or a combination of both) of a suitable precursor [5-7], catalytic activation using metal salts or organometallic compounds [8-11], carbonization of polymer blends [12-15], carbonization of an organic gel synthesized under different drying conditions (xerogel, cryogel or aerogel) [16-18], among most representative. Our earlier investigations focused on the synthesis of nanoporous carbons based on biomass and coal treatment products. Previous studies reported the preparation of synthetic carbons from polyolefine wax [19], furfural [20] and mixtures of tar from carbonization of agricultural by-products and furfural [21]. We have observed that the chemical composition of the precursor vastly influences the structure and properties of the obtained carbon. For instance, the solid product -the carbonizate before activation- obtained from a given raw material containing dominantly aromatic compounds (such as biomass-derived tar), is characterized by a dense structure and weak reactivity towards steam activation. On the contrary, when furfural is used as precursor, the final carbon 
material is less dense and more reactive, due to the insertion of oxygen in the carbon skeleton that favors the formation of pores during the activation process. Taking this into account, the aim of our investigations was to explore the development of a synthetic route for the production of nanoporous carbons with different porous structure and chemical features, on the base of an adequate combination of precursor materials and methods of treatment. For this purpose, coal tar pitch and furfural were chosen as raw materials (precursors), as they exhibit very different chemical composition and properties. Moreover, -as it was noted in previous studies- the carbonizates obtained from each of them are well distinguished by their structure and reactivity [19-21]. The present work is dedicated to exploring the influence of the composition of the initial precursor's mixture and the treatment conditions on the final physicochemical and electrical properties of produced nanoporous carbons. Varying the chemical composition of the raw materials would allow us to influence the processes of formation of the texture and structure of the final product. The prepared carbon materials have been fully characterized and investigated as electrodes in an electrochemical application.

\section{Experimental}

\section{Synthesis procedure}

The mixtures of coal tar pitch and furfural in different proportions (ranging from 30 to $60 \mathrm{wt} . \%$ ) were treated with concentrated $\mathrm{H}_{2} \mathrm{SO}_{4}$ (drops of $\mathrm{H}_{2} \mathrm{SO}_{4}$ were added to the mixtures with continuous stirring) at $120{ }^{\circ} \mathrm{C}$ until solidification. The obtained solid product was heated at $600{ }^{\circ} \mathrm{C}$ in a covered silica crucible with a heating rate of $10{ }^{\circ} \mathrm{C} \min ^{-1}$ under nitrogen atmosphere. The obtained solid product after carbonization was further submitted to steam activation at $800^{\circ} \mathrm{C}$ during 1 hour for synthesizing the porous carbon. The samples were labelled as $\mathrm{F}$ followed by the content in furfural. In order to explore the effect of a thermal heating at high temperature of the carbons on the electrochemical performance, selected samples were submitted to an additional heat treatment 
under nitrogen atmosphere. Sample F50 was treated at $1100{ }^{\circ} \mathrm{C}$ and sample F55 was heated at $1400{ }^{\circ} \mathrm{C}$. The samples submitted to this additional heat treatment were labeled as $\mathrm{H}$ (carbon $\mathrm{F} 55 \mathrm{H}$ ).

\section{Porous characterization}

Nanotexture of the synthesized carbon materials was characterized by $\mathrm{N}_{2}$ adsorption at $-196{ }^{\circ} \mathrm{C}$, carried out in an automatic volumetric apparatus (ASAP 2020 from Micromeritics). Before the experiments, the samples were outgassed under vacuum at $250{ }^{\circ} \mathrm{C}$ for overnight. The isotherms were used to calculate the specific surface area, $\mathrm{S}_{\mathrm{BET}}$, pore volumes and pore size distributions; the latter by using the DFT method [22].

\section{Oxygen-containing functional groups}

The amount of oxygen-containing functional groups with increasing acidity on the carbon surface was determined applying Boehm's method by neutralization with basic solutions of increasing strength - $\mathrm{NaHCO}_{3}$, $\mathrm{Na}_{2} \mathrm{CO}_{3}, \mathrm{NaOH}$, and $\mathrm{C}_{2} \mathrm{H}_{5} \mathrm{ONa}-$. About $0.5 \mathrm{~g}( \pm 0.0001 \mathrm{~g})$ of the carbon was put in contact with $100 \mathrm{ml}$ of 0.05 $\mathrm{N}$ base solution in sealed flasks. The suspensions were shaken at least 16 hours, and then filtered. The excess of base remaining in the solution was determined from back-titration after adding an excess of standard $\mathrm{HCl}$ solution [23]. The amount of basic sites was determined with $0.05 \mathrm{~N} \mathrm{HCl}$ [24]. The procedure is the same as above mentioned, as back-titration of the excess of $\mathrm{HCl}$ was performed using titration with $0.05 \mathrm{~N} \mathrm{NaOH}$ solution.

\section{pH determination}

The $\mathrm{pH}$ of the carbons was measured according to the following procedure: $4.0 \mathrm{~g}$ of carbon was weighed into a $250 \mathrm{~mL}$ beaker, and $100 \mathrm{~mL}$ of water was added. The beaker was covered with a watch glass, and the mixture was boiled for $5 \mathrm{~min}$. The suspension was set aside, and the supernatant liquid was poured off at $60{ }^{\circ} \mathrm{C}$. The decanted portion was cooled down to ambient temperature and its $\mathrm{pH}$ was measured to the nearest $0.1 \mathrm{pH}$ unit.

\section{Cell assembly}


The electrodes were prepared from a mixture of $90 \mathrm{wt} . \%$ activated carbon powder and $10 \mathrm{wt} . \%$. polytetrafluoroethylene (PTFE binder (Aldrich, 60\% suspension in water) and pressed on aluminum discs

(surface area $1.75 \mathrm{~cm}^{2}$ ). The electrodes were soaked in the electrolyte before the cell assembly. Sandwich-type symmetric cells constituted of two carbon electrodes of comparable mass and electrically isolated by a ceramicmat separator were built in a dry-box under argon. The cells were enclosed in a metallic hermetically closed can. Propylene carbonate solutions containing $1 \mathrm{M}$ tetraetylamonium tetrafluoroborate $\left(\mathrm{Et}_{4} \mathrm{NBF}_{4}\right)$, (Aldrich p.a.) were used as electrodes (containing $<20$ ppm water).

\section{Results and discussion}

\section{Synthesis and characterization of the materials}

The characterization of initial pitch is valuable for understanding the processes taking place during the preparation and modification of the precursor mixture with $\mathrm{H}_{2} \mathrm{SO}_{4}$. Table 1 shows, that pitch precursor possesses relatively low softening point temperature. The elemental analysis data indicate that the amount of oxygen containing structures is not high, whereas the high $\mathrm{C} / \mathrm{H}$ ratio indicates the presence of considerable amount of aromatic species in the pitch.

An exhaustive characterization of the pitch was carried out by Soxhlet extraction with chloroform, following the scheme of Figure 1. The results of the solubility class separation of the neutral, basic and acidic fractions of the pitch are also compiled in Table 1.

It can be observed that the raw pitch contains predominantly neutral compounds, with a considerable fraction of organic basic species. These results point out that the raw pitch studied contains a relatively small amount of reactive structures, which could be involved in condensation and polymerization reactions leading to the formation of higher molecular products (i.e., formation of solid products). Thus, it is necessary to modify the pitch to facilitate the solidification of the precursor allowing to further synthesize nanoporous carbons. In this 
regard, earlier studies carried out in our research group have shown that furfural resin is a suitable oxygencontaining raw material for the production of carbon adsorbents with a large number of oxygen-containing groups on the surface [20]. Furfural is an accessible and cheap material that accelerates the polymerization processes in the mixtures. Indeed, carbon adsorbents with different structure and properties have been prepared from mixtures of furfural and biomass-derived tars, while optimizing the operating conditions (including the composition of the mixtures, activation reagents, pre-treatment of the precursors, etc.) [21]. As the biomassderived tar possess large number of oxygen-containing structures, in order to control the amount of oxygen in the initial mixture, we decided to substitute it by coal tar pitch, which contains mainly aromatic substances. For this reason, we have added furfural to the coal tar pitch used as precursor, aiming at incorporating a reactive structure in the carbon matrix capable to induce polymerization and polycondensation reactions that will allow us to easily promote the solidification of the mixture. The resulting solid product was carbonized and submitted to steam activation to produce a suitable nanoporous carbon.

Mixtures containing different amounts of furfural (ranging from 30 to $60 \mathrm{wt} . \%$ ) were investigated as precursors for the preparation of carbon materials. As indicated in the experimental section, the mixtures were treated with conc. $\mathrm{H}_{2} \mathrm{SO}_{4}$ until solidification and the obtained solid product was heated up to $600{ }^{\circ} \mathrm{C}$ under nitrogen atmosphere, followed by steam activation at $800^{\circ} \mathrm{C}$ for 1 hour. The main chemical composition parameters of the synthesized carbons are presented in Table 2.

Data show that the furfural content of the initial mixture has a strong influence on the chemical composition of the resulting carbons. Along with the prevailing content of aromatic structures in the pitch, the increasing trend in the oxygen content as the furfural amount in the initial mixture is rising, unambiguously indicates that inserting oxygen in the carbon precursor to the formation of oxygen containing structures on the surface of the final product. The prepared carbons also display strong alkaline character, as inferred from the $\mathrm{pH}$ values. A more detailed analysis of the nature of the oxygen functionalities inserted in the carbon materials due to the 
incorporation of furfural in the precursor is shown in Table 3. The Boehm titration analysis reveals that most of the surface functionalities are of weak acid nature, although basic groups are also created. The amount of acidic groups (mainly carbonyl groups) increases with the furfural content, although the amount of functionalities of basic nature does not seem to follow the same trend, being almost constant in all the samples. On the other hand, the thermal treatment at high temperatured caused a sharp decrease in the amount of oxygen surface groups, both of acidic and basic nature. Consequently, the overall samples after the thermal treatment become more basic. The obtained results indicate the possibility for adjusting the content of oxygen groups on the carbon surface by varying the amount of furfural in the initial mixture.

It should be mentioned that such combination of chemical features (i.e., high oxygen content and basic character) is rather unusual in porous carbons. This might be attributed to the furfural present in the precursor mixture, which would facilitate the insertion of oxygen within the carbonaceous matrix -likely as ether, furanic and/or chromene-like structures-, as opposed to the majority of activated carbons where they are typically located at the edges of the basal planes in the graphene layers. According to literature, carbons obtained from cork also give rise to materials with these unusual chemical properties [25, 26].

The composition of the mixture precursor also affects the development of the porosity after activation of the solid product. The iodine number was initially y employed as an indicator of the surface area of the prepared carbons, since it is known that this parameter provides a close to the BET surface area determined by $\mathrm{N}_{2}$ adsorption [27]. It can be observed that the iodine number increases wit the furfural content, suggesting that the mixtures containing bigger amount of furfural are more reactive and not too firm due to the presence of higher amount of oxygen in its composition (Table 4). Consequently, the steam activation of the solid products prepared with a higher furfural ratio would allow an easier development of porosity. The beneficial effect of the incorporation of oxygen species on a carbon precursor on the development of the porous network has been reported in earlier investigations, where it was reported that the preoxidation of a bituminous coal gives rise to a 
better development of a microporous network [28]. The decrease in the yield of the final product (carbon yield) with rising the furfural content in the initial mixture also confirms this observation.

The X-ray diffraction patterns of the prepared carbons also clarify this issue and corroborates the easier formation of a porous network in the samples obtained from mixture with higher content of furfural. The XRD patterns of the samples clearly show the reflections (002) and (100) associated to the presence of graphitic structures. Reflection (002) in the patterns of the studied samples shows a clear shifting towards lower scattering angles $2 \theta$ with increasing the furfural content, indicating the typical turbostratic structure with interlayer distances of graphenes substantially higher than those in graphite. From the position of the (002) peak we can calculate an estimate of the interplanar spacing, $d_{002}$, by direct application of Bragg's Law -the values of selected samples are given in Table 5-, and obtained values show a slight increase with the furfural content in the precursor mixture.

Estimates of mean crystallite dimensions can generally be obtained from XRD data by application of the Debye-Scherrer equation, providing information about the height and width of the crystallites (Lc and La parameters, respectively). The crystalline width $\mathrm{L}_{\mathrm{a}}$ parameter is significant greater for the carbons with the lowest furfural content, whereas the crystalline height Lc follows the opposite trend. This indicates that the carbons synthesized from mixtures with a higher amount of coal tar pitch possess more ordered and compact structures, which confirms the above-mentioned finding about their larger stability towards the activation step. Furthermore, it was found that with increasing the furfural content the mean number of layer planes in the crystallites decreased, corroborating the disorganized structure of the carbons created by the furfural.

Based on the preliminary data provided by the iodine number, the pore structure of selected carbons was investigated by gas adsorption. The nitrogen adsorption isotherms at $-196^{\circ} \mathrm{C}$ of the samples with the higher iodine numbers (namely F45, F50 and F55) were recorded (Figure 2) with the exception of F60, which was discarded due to its low carbon yield. The main textural parameters of the prepared carbons obtained from the 
analysis of the nitrogen adsorption isotherms are compiled in Table 6 . The surface area of selected commercial carbons widely used in electrochemical applications has also been included for comparison reasons. It can be observed from this data that the furfural content has a strong effect in the porosity of the resulting carbons. The sample with the lowest proportion of furfural (F45) exhibits a type I isotherm in the BDDT classification [29], indicative of a microporous material. As the content of furfural rises, the isotherms gradually become type I/IV, with a clear opening of the knee at low relative pressures. This indicates the development of mesoporosity and a widening of the microporosity in the samples F50 and F55.

This observation was confirmed by the analysis of the PSD by the DFT method (Table 6 and Figure 2). Rising the furfural content in the initial mixture from $45 \%$ to $55 \%$ leads to significant increase of the volume of the micropores (a two-fold increase from F45 to F55) as well as the volume of mesopores (i.e., 6 times larger).

The textural data of selected samples submitted to heating at high temperatures (between $1100-1400{ }^{\circ} \mathrm{C}$ ) is also shown in Figure 2 and Table 6. In this regard, it has been reported that the presence of oxygenated groups enhances the inner resistance and the leakage current [30] of carbon electrodes. Taking into account the large amount of oxygen-containing functionalities of the carbons herein reported (Table 1) due to the incorporation of furfural in the synthesis, it is reasonable to expect a high resistance in these materials. Consequently, two carbons were submitted to a thermal treatment at high temperature in order to remove the surface functionalities. On the other hand, it is also known that heating at high temperature may favour internal rearrangements in the carbon structure, which depending on the carbon precursor can end up with an increase in the electrical conductivity if graphitic-like domains are created during the rearrangements. However, thermal treatment may also cause important modifications in the textural and structural properties of the carbon skeleton (annealing effects) $[31,32]$ thus it becomes necessary to investigate the porosity of the samples after thermal treatment. The results show a decrease in the surface area and pore volumes of the treated carbons, which is more important in the case of $\mathrm{F} 55 \mathrm{H}$ (treated at a highest temperature), and more precisely in the mesopore 
volume. In this case, it seems that the structural modification of the carbon occurs to a small extent, due to the high temperature applied (Table 5).

Summarizing, nanoporous carbons with tailored porous features and chemical composition can be synthesized from mixtures of coal tar pitch and furfural in different proportions. The resulting carbons possess unique characteristic of high surface area, high oxygen content and basic nature.

\section{Electrochemical performance of the carbon materials as electrodes in supercapacitors}

A selection of the carbons prepared from mixtures of coal tar pitch and furfural have been investigated for their use as electrodes in supercapacitors. It is well-known that highly microporous carbons with large pore volumes are desirable for electrochemical energy storage, since they enable high values of capacitance [1,2]. For this reason, samples F50 and F55 and their corresponding counterparts after heating at high temperature (series H) have been investigated as electrode materials in supercapacitors. The dependence of the capacity with the discharging current for the different carbons is presented in Figure 3. For comparison reasons, the performance of two carbons commercialized by Norit for this application have also been included.

It should be pointed out that at low current densities (below $80 \mathrm{~mA} / \mathrm{g}$ ), the electrochemical performance of sample F55 is lower than that of F50, despite the former has a higher surface area and more developed porous structure (Figure 2 and Table 6). However, the PSD of F50 revealed a larger contribution of micropores of dimensions below $1 \mathrm{~nm}$, which confirms previous finding in the literature on the importance of the pore dimensions in the electrochemical performance of supercapacitors [33, 34]. At high current densities (above $100 \mathrm{~mA} / \mathrm{g}$ ), F55 outperforms F50, which capacitance fading is steeper. This observation could be attributed to the accessibility (kinetic) restrictions of the electrolyte ions when the device is operating at high current density, since the transport pore network (mesoporosity) of carbon F50 is lower than that of F55. It seems evident thus that the presence of pores of larger sizes becomes important when fast charge propagation conditions 
are needed. Compared to commercial carbons, the results show that samples F50 and F55 showed a better performance than that of the carbon with the lowest surface area (Norit NK-1, surface area $600 \mathrm{~m}^{2} / \mathrm{g}$, supplied by manufacturer) regardless the current density. However, they show a slightly lower electrochemical response when compared to Norit SX-Ultra which has a similar value of surface area $\left(1200 \mathrm{~m}^{2} / \mathrm{g}\right.$ supplied by manufacturer). This fact could be attributed to the high resistivity observed in these materials, since the electrodes are composed of the active carbon material and a binder (without any conductive additive). To confirm this fact, the performance of a carbon electrode constituted of a mixture of F50 and a conductive additive (natural graphite, $10 \mathrm{wt} . \%$ ) was also investigated (sample F50+NG). It can be observed in figure 3 that the capacitance of carbon F50 was largely enhanced after the addition of the conductive additive; moreover, the capacitance fading with the current density is also softened. Indeed, measurement of the electroresistance of the cells show rather high values for the electrodes without conductive additive (75 and 110 ohms for samples F50 and F55, respectively), between 2-3 times larger than those measured for the commercial carbons (50 and 25 ohms for Norit NK-1 and Norit SX-Ultra, respectively).

From the electrochemical performance of carbons F50 and F55 it seems that rising the furfural content decreases the specific capacitance (Figure 3) and increases the resistance of the carbon electrodes. This could be attributed to the large number of oxygen functionalities present in carbon F55 (Tables 2 and 3), which would also affect its capacity. The detrimental effect of oxygen functionalities on the electrochemical performance of carbon electrodes has also been reported in the literature [35].

As for the samples submitted to thermal treatment, Figure 3 shows that the fall in capacitance with increasing the current density is less pronounced for the $\mathrm{H}$ series (both $\mathrm{F} 50 \mathrm{H}$ and $\mathrm{F} 55 \mathrm{H}$ ). This is likely due to the double effect of the thermal treatment (removal of the surface functional groups and increasing the electrical conductivity of the material). Indeed, the electrical conductivity of the heat treated simples also decreases (i.e., 110 and 76 ohms for samples F55 and F55H, respectively). 
Summarizing, the obtained results show the possibilities to adjust the properties of the synthesized carbons obtained on the base of mixtures of coal tar pitch and furfural varying the proportion of the components. These investigations show the paths for further optimization of the properties of the synthesized carbons by selection of appropriate additional treatments of the final products. The electrochemical performance of the electrodes built with the prepared carbon and a conductive additive is very promising (specific capacitance of $110 \mathrm{~F} \mathrm{~g}^{-1}$ ), which makes this application an attractive field for further research with these materials.

\section{Conclusions}

The results reported in this work show that mixtures of coal tar pitch -ingredient containing mainly non-reactive aromatic structures- and furfural -reactive ingredient inclined to polymerization reactions- are appropriate raw materials for the synthesis of nanoporous carbons with negligible ash content. The specific surface area and amount of oxygen containing groups on the carbons surface significantly depend on the composition of the mixture. The activation process is faster and leads to formation of a well-developed porous structure when the furfural content of the precursor mixture increases. The carbonaceous material obtained from mixtures containing less furfural -after the carbonization step- is characterized by a more ordered and more stable structure, making the sample less reactive upon the activation step.

By varying the chemical composition of the initial mixture, while keeping the same synthesis condition, it is possible to adjust the porous structure, chemical composition and electro resistance of the obtained carbons. In general, increasing the furfural content in the precursor also increases the surface area and pore volumes, as well as the amount of oxygen groups of basic nature. The electrodes composed of the synthesized carbons exhibit specific capacitance values close to those of commercial carbons, although they are rather resistive. Notwithstanding, treating the carbons at high temperatures (series $\mathrm{H}$ ) decreases the resistivity, while the capacitance increases and the textural features of the carbons are preserved. 
Acknowledgements: The authors acknowledge financial support for this work from MEJS-NFSI, Bulgaria

(Award 02-222/17.12.2008)

\section{References}

[1] T.J. Bandosz (Ed.) in Activated carbon surfaces for environmental remediation, in the series Interface Science and Technology, Elsevier, 2006, New York.

[2] Y. Gogotsi (Ed.) in Carbon Nanomaterials, CRC Press, Taylor \& Francis Group, 2006, Boca Raton, Florida.

[3] M. Inagaki (Ed.) in New carbons: control of structure and functions, Elsevier Science Ltd, 2000, Oxford.

[4] J Lee, J Kim, T Hyeon, Recent progress in the synthesis of porous carbon materials, Adv. Mater., 2006, 18, 2073-2094

[5] H Marsh, F. Rodriguez-Reinoso in Activated Carbon, Elsevier Science 2006, Oxford, UK.

[6] Z. Hu, M. P. Srinivasan, Y. Ni, Preparation of mesoporous high-surface-area activated carbon Adv. Mater. 2000; 12: 62- 65.

[7] KC Roh, JB Park, C-T Lee, CW Park, Study on synthesis of low surface area activated carbons using multi-step activation for use in electric double layer capacitor. Journal of Industrial and Engineering Chemistry 2008;14: 247-251.

[8] H. Marsh, B. Rand. The process of activation of carbons by gasification with CO2-II. The role of catalytic impurities. Carbon 1971; 9: 63-72.

[9] D Hines, A. Bagreev, T.J. Bandosz, Surface properties of porous carbon obtained from polystyrene sulfonic acid-based organic salts, Langmuir 20 (2004) 3388.

[10] H. Tamai, T. Kakii, Y. Hirota, T. Kummamoto, H. Yasuda. Synthesis of Extremely Large Mesoporous Activated Carbon and Its Unique Adsorption for Giant Molecules Chem. Mater. 1996; 8: 454- 462.

[11] A. Oya, S. Yoshida, J. Alcaniz-Monge, A. Linares-Solano. Formation of mesopores in phenolic resinderived carbon fiber by catalytic activation using cobalt. Carbon 1995; 33: 1085- 1090.

[12] N. Patel, K. Okabe, A. Oya. Designing carbon materials with unique shapes using polymer blending and coating techniques. Carbon 2002; 40: 315-320.

[13] J. Ozaki, N. Endo, W. Ohizumi, K. Igarashi, M. Nakahara, A. Oya. Novel preparation method for the production of mesoporous carbon fiber from a polymer blend. Carbon 1997; 35: 1031-1133.

[14] A. Oya, N. Kasahara. Preparation of thin carbon fibers from phenol-formaldehyde polymer micro-beads dispersed in polyethylene matrix. Carbon $2000 ; 38: 1141-1144$.

[15] J. Alcaniz-Monge, D. Cazorla-Amores, A. Linares-Solano, A. Oya, A. Sakamoto, K. Hoshi. Preparation of general purpose carbon fibers from coal tar pitches with low softening point, Carbon 1997; 35: 10791087.

[16] R. W. Pekala. Organic aerogels from the polycondensation of resorcinol with formaldehyde, J. Mater. Sci. 1989; 24: 3221-3227.

[17] R. W. Pekala, C. T. Alviso, F. M. Kong, S. S. Hulsey. Aerogels derived from multifunctional organic monomers . J. Non-Cryst. Solids 1992; 145: 90- 98.

[18] R. W. Pekala, D. W. Schaefer. Structure of organic aerogels. 1. Morphology and scaling. Macromolecules 1993;26(20):5487-5493. 
[19] N. Petrov, T. Budinova. Oxidized carbon from polyolefine wax. Chemie Ingenieur Technic 1992;64:6466.

[20] N.Petrov, T.Budinova, M.Razvigorova et al. Preparation and characterization of carbon adsorbents from furfural. Carbon 2000;38:2069-2075.

[21] D.Savova, E.Apak, E.Ekinci, F.Yardim, N.Petrov et al. Biomass conversion to carbon adsorbents and gas. Biomasa Bioenergy 2001; 21:133-142.

[22] J. Olivier, Improving the models used for calculating the size distribution of micropore volume of activated carbons from adsorption data, Carbon 36 (1998) 1469-1472.

[23] H.P. Boehm, in: D.D. Eley, H. Pines, P.B.Weisz (Eds.), Chemical Identification of Surface Groups, Advances in Catalysis, vol. 16, Academic Press, NewYork, 1966, 179-274.

[24] Papirer E, Li S, Donnet J-B. Contribution to the study of basic surface groups on carbons, Carbon, 1987:25(2);243- 247.

[25] Carrott, P.J.M., Ribeiro-Carrott, M.M.L., Lima, R.P., 1999. Preparation of activated carbon "membranes" by physical and chemical activation of cork. Carbon 37, 515-517.

[26] Mestre AS, Pires J, Nogueira JMF, Parra JB, Carvalho AP, Ania CO, Waste-derived activated carbons for removal of ibuprofen from solution: Role of surface chemistry and pore structure, Bioresource Technology 100 (2009) 1720-1726.

[27] M. Molina-Sabio, C. Salinas-Martinez de Lecea, F. Rodriguez-Reinoso, C. Puente-Ruiz, A. Linares Solano. A comparison of different tests to evaluate the apparent surface area of activated carbons. Carbon 1985;23:91-96.

[28] B Ruiz, JB Parra, JA Pajares, JJ. Pis, Study of porous development in pyrolysis chars obtained from a low-volatile coal, J Anal. Appl. Pyrol. 58-59 (2001) 873-886

[29] Brunauer, B., Deming, L.S., Deming, W.E., Teller, E., 1940. On a theory of the van der Waals adsorption of gases. J. Am. Chem. Soc. 62, 1723-1732.

[30] CT. Hsieh, H. Teng, Influence of oxygen treatment on electric double-layer capacitance of activated carbon fabrics. Carbon, 40 (2002) 667-674.

[31] A.M. Rao, A.W.P. Fung, M.S. Dresselhaus, M. Endo, Structural characterization of heat-treated activated carbon fibers, J. Mater. Res. 7 (1996) 1788-1794;

[32] CO Ania, JA Menendez, JB. Parra, JJ. Pis, Microwave-induced regeneration of activated carbons polluted with phenol: a comparison with conventional thermal regeneration, Carbon 42 (2004) 1377-1381.

[33] Mysyk R, Raymundo-Pinero E, Beguin F. Saturation of subnanometre pores in an electric double-layer capacitor. Electrochem. Commun. 11, 554-556 (2009)

[34] C Largeot, C Portet, J Chmiola, PL Taberna, Y Gogotsi, P Simon, Relation between the Ion Size and Pore Size for an Electric Double-Layer Capacitor, J. Am. Chem. Soc., 2008, 130 (9), 2730-2731

[35] Bleda-Martinez MJ, Macia-Agullo JA, Lozano-Castelo D, Morallon E, Cazorla-Amoros D, LinaresSolano A. Role of surface chemistry on electric double layer capacitance of carbon Materials. Carbon, 2005:43;2677-2684. 
Table 1. Elemental analysis of the coal tar pitch (wt.\%) and solubility class separation of CHS part of pitches determined by sequential Soxhlet extraction of the pitch precursor

\begin{tabular}{|c|c|c|c|c|c|c|c|}
\hline \multirow{2}{*}{\multicolumn{2}{|c|}{ Softening point $\left({ }^{\circ} \mathrm{C}\right)$}} & \multicolumn{6}{|c|}{ Elemental Analysis (wt.\%) } \\
\hline & & $\mathbf{C}$ & $\mathbf{H}$ & $\mathbf{N}$ & S & $\mathbf{O}$ & $\mathbf{C} / \mathbf{H}$ \\
\hline Pitch & 72 & 90.90 & 4.95 & 0.90 & 0.50 & 2.75 & 1.53 \\
\hline \multicolumn{8}{|c|}{ Solubility class separation of chloroform soluble parts (wt.\%) } \\
\hline & Neutral part & \multicolumn{2}{|c|}{ Phenols } & \multicolumn{2}{|c|}{ Bases } & \multicolumn{2}{|c|}{ Acids } \\
\hline & 87.58 & \multicolumn{2}{|c|}{2.37} & \multicolumn{2}{|c|}{8.86} & \multicolumn{2}{|c|}{1.19} \\
\hline
\end{tabular}

Table 2. Chemical composition of the carbon adsorbents obtained from mixtures of furfural and coal tar pitch

\begin{tabular}{llllccccc}
\hline & \multirow{2}{*}{ Moisture } & \multirow{2}{*}{ Ash } & \multirow{2}{*}{ pH } & \multicolumn{5}{c}{ Elemental Analysis (wt.\%) } \\
\cline { 5 - 9 } & & & & C & H & N & S & O diff $^{\text {F60 }}$ \\
\cline { 5 - 8 } & 5.8 & 0.6 & 8.4 & 80.3 & 2.3 & 0.3 & 0.3 & 16.8 \\
F55 & 5.6 & 0.7 & 7.9 & 80.8 & 2.4 & 0.3 & 0.4 & 16.1 \\
F50 & 5.1 & 0.7 & 7.6 & 81.1 & 2.6 & 0.3 & 0.5 & 15.5 \\
F45 & 5.4 & 0.8 & 7.5 & 81.6 & 2.6 & 0.3 & 0.6 & 14.9 \\
F40 & 5.5 & 0.8 & 7.5 & 82.2 & 2.7 & 0.3 & 0.7 & 14.1 \\
F30 & 5.2 & 0.9 & 7.3 & 82.9 & 2.7 & 0.3 & 0.7 & 13.4 \\
\hline
\end{tabular}


Table 3. Nature of the oxygen groups on surface of the prepared carbons, obtained by Boehm titration

\begin{tabular}{lcccccc}
\hline & \multicolumn{5}{c}{ Acidic groups (meq g $\mathbf{~}^{\mathbf{1}}$ ) } & $\begin{array}{c}\text { Total } \\
\text { Basic }\end{array}$ \\
\cline { 2 - 6 } & Carboxylic & Lactone & $\begin{array}{l}\text { Phenolic, } \\
\text { hydroxyl }\end{array}$ & Carbonyl & $\begin{array}{c}\text { Total } \\
\text { Acidic }\end{array}$ & $\begin{array}{c}\text { groups } \\
\left(\mathbf{m e q}^{-\mathbf{1}}\right)\end{array}$ \\
\hline F45 & 0.012 & 0.011 & 0.026 & 0.550 & 0.599 & 0.592 \\
F50 & 0.019 & 0.015 & 0.047 & 0.658 & 0.739 & 0.585 \\
F55 & 0.024 & 0.029 & 0.085 & 0.839 & 0.977 & 0.575 \\
F60 & 0.043 & 0.049 & 0.201 & 1.093 & 1.386 & 0.555 \\
F50H & BDL & BDL & 0.072 & 0.120 & 0.192 & 0.192 \\
F55H & BDL & BDL & 0.005 & 0.057 & 0.062 & 0.064 \\
\hline
\end{tabular}

BDL- below detection limit

Table 4. Iodine number and carbon yield of the materials obtained from mixtures of furfural and coal tar pitch

\begin{tabular}{lllllll}
\cline { 2 - 6 } & F60 & F55 & F50 & F45 & F40 & F30 \\
\hline Iodine number (mg/g) & 1380 & 1420 & 1210 & 1100 & 900 & 750 \\
Carbon yield (wt.\%) & 35 & 45 & 49 & 53 & 58 & 62 \\
\hline
\end{tabular}


Table 5. Main parameters obtained from XRD patterns of selected carbonizates prepared from different mixtures

\begin{tabular}{|c|c|c|c|}
\hline \multirow[t]{2}{*}{$\mathrm{X}$-ray data } & \multicolumn{3}{|c|}{ Sample } \\
\hline & F30 & F55 & F55H \\
\hline Position 002 & $2 \theta=24.75^{\circ}$ & $2 \theta=24.45^{\circ}$ & $2 \theta=24.46^{\circ}$ \\
\hline $\begin{array}{l}\mathrm{d}_{002} \text { (distance between } \mathrm{C} \text { atoms of } \\
\text { adjacent planes) }\end{array}$ & $0.3597 \mathrm{~nm}$ & $0.3640 \mathrm{~nm}$ & $0.3639 \mathrm{~nm}$ \\
\hline $\begin{array}{l}\text { Max number of lamellas in a } \\
\text { crystallite }\end{array}$ & $\sim 5$ & $4-5$ & $4-5$ \\
\hline Position 100 & $2 \theta=43.58^{\circ}$ & $2 \theta=43.32^{\circ}$ & $2 \theta=43.44^{\circ}$ \\
\hline $\begin{array}{l}d_{100} \text { (distance between } C \text { atoms in } \\
\text { the plane) }\end{array}$ & $0.2077 \mathrm{~nm}$ & $0.2089 \mathrm{~nm}$ & $0.2083 \mathrm{~nm}$ \\
\hline Crystallite size 002 & & & \\
\hline $\begin{array}{l}-\mathrm{IB} \\
-\mathrm{FWHM}\end{array}$ & $\begin{array}{l}\mathrm{Lc}=0.96 \mathrm{~nm} \\
\mathrm{Lc}=1.34 \mathrm{~nm}\end{array}$ & $\begin{array}{l}\mathrm{Lc}=0.82 \mathrm{~nm} \\
\mathrm{Lc}=1.15 \mathrm{~nm}\end{array}$ & $\begin{array}{l}\mathrm{Lc}=0.93 \mathrm{~nm} \\
\mathrm{Lc}=1.30 \mathrm{~nm}\end{array}$ \\
\hline $\begin{array}{l}\text { Crystallite size } 100 \\
\text { - IB } \\
\text { - FWHM }\end{array}$ & $\begin{array}{l}\mathrm{La}=1.27 \mathrm{~nm} \\
\mathrm{La}=1.77 \mathrm{~nm}\end{array}$ & $\begin{array}{l}\mathrm{La}=1.14 \mathrm{~nm} \\
\mathrm{La}=1.58 \mathrm{~nm}\end{array}$ & $\begin{array}{l}\mathrm{La}=1.21 \mathrm{~nm} \\
\mathrm{La}=1.66 \mathrm{~nm}\end{array}$ \\
\hline
\end{tabular}

$\lambda(\mathrm{Cu} \mathrm{K \alpha})=0.1542 \mathrm{~nm}$

$I B$ - (estimated by) integration

FWHM - (estimated by) full width at half maximum

Table 6. Main textural parameters of the catalysts obtained from $\mathrm{N}_{2}$ adsorption isotherms at $77 \mathrm{~K}$

\begin{tabular}{|c|c|c|c|c|c|}
\hline & $\begin{array}{c}\mathrm{S}_{\mathrm{BET}} \\
{\left[\mathrm{m}^{2} \mathbf{g}^{-1}\right]}\end{array}$ & $\begin{array}{l}V_{\text {TOTAL }}{ }^{a} \\
{\left[\mathrm{~cm}^{3} \mathrm{~g}^{-1}\right]}\end{array}$ & $\begin{array}{l}V_{\text {MICRO }}{ }^{b} \\
{\left[\mathrm{~cm}^{3} \mathrm{~g}^{-1}\right]}\end{array}$ & $\begin{array}{c}V_{\text {MESO }}{ }^{b} \\
{\left[\mathrm{~cm}^{3} \mathrm{~g}^{-1}\right]}\end{array}$ & $\begin{array}{c}\mathrm{Wo} \mathrm{N}_{2}{ }^{\mathrm{c}} \\
{\left[\mathrm{cm}^{3} \mathrm{~g}^{-1}\right]}\end{array}$ \\
\hline F45 & 678 & 0.316 & 0.213 & 0.030 & 0.255 \\
\hline F50 & 1173 & 0.551 & 0.374 & 0.033 & 0.533 \\
\hline F50H & 1071 & 0.486 & 0.338 & 0.033 & 0.473 \\
\hline F55 & 1613 & 0.761 & 0.492 & 0.177 & 0.604 \\
\hline F55H & 1397 & 0.620 & 0.440 & 0.074 & 0.509 \\
\hline
\end{tabular}

a evaluated at relative pressures of 0.99

${ }^{\mathrm{b}}$ evaluated by DFT method applied to $\mathrm{N}_{2}$ adsorption data using slit-shaped pore model

${ }^{c}$ evaluated by DR approach 


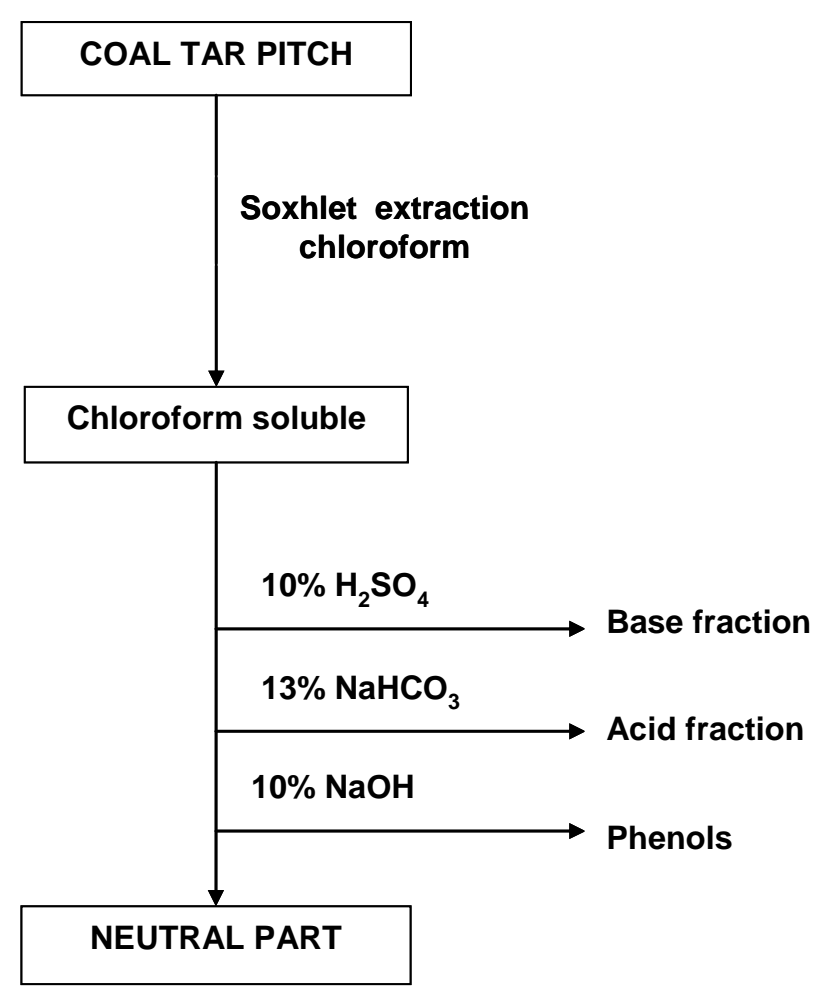

Figure 1. Scheme of separation of coal tar pitch. 

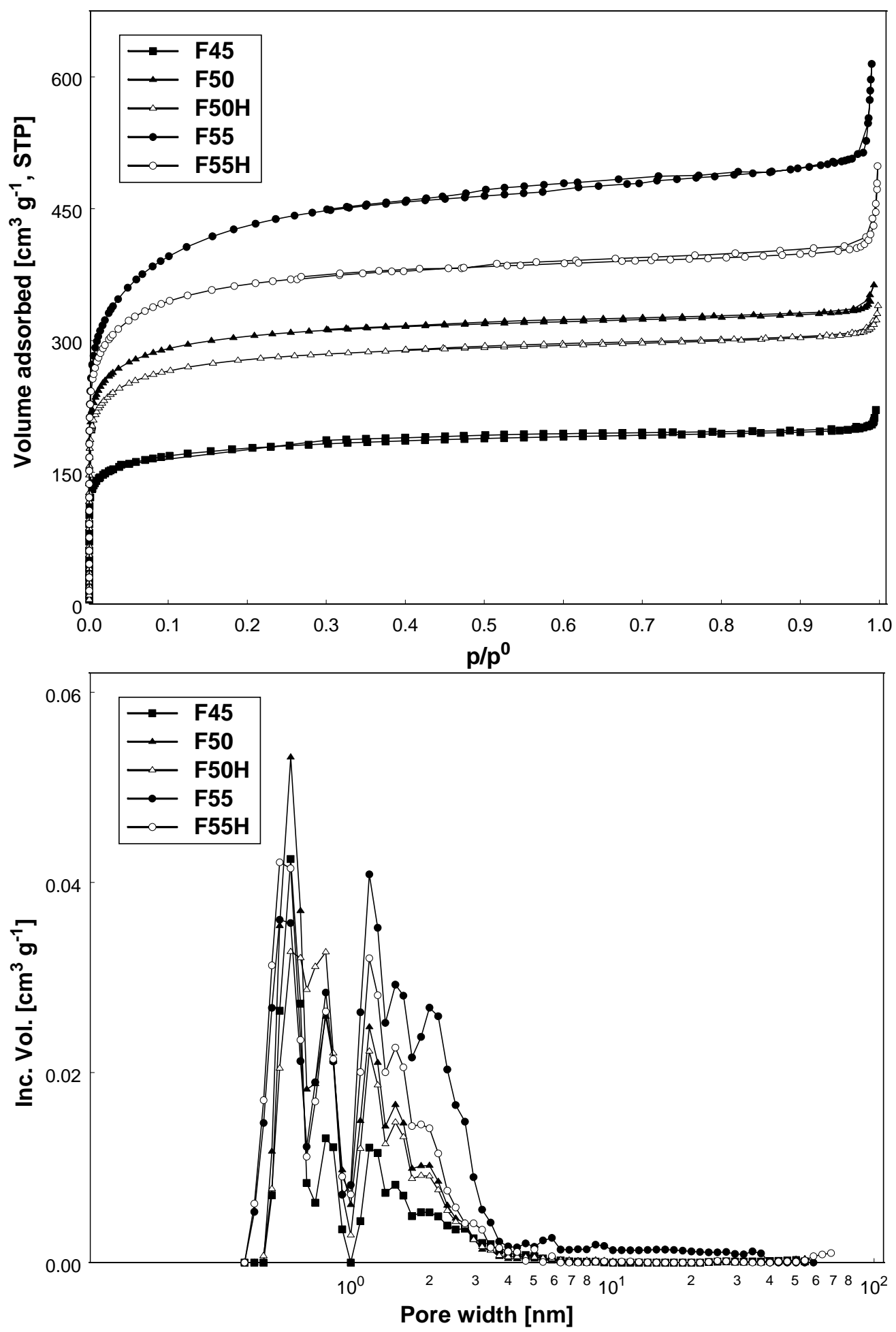

Figure 2. $\mathrm{N}_{2}$ adsorption isotherms (left) at $-196^{\circ} \mathrm{C}$ and pore size distributions (right) obtained by DFT method of synthesized carbons. 


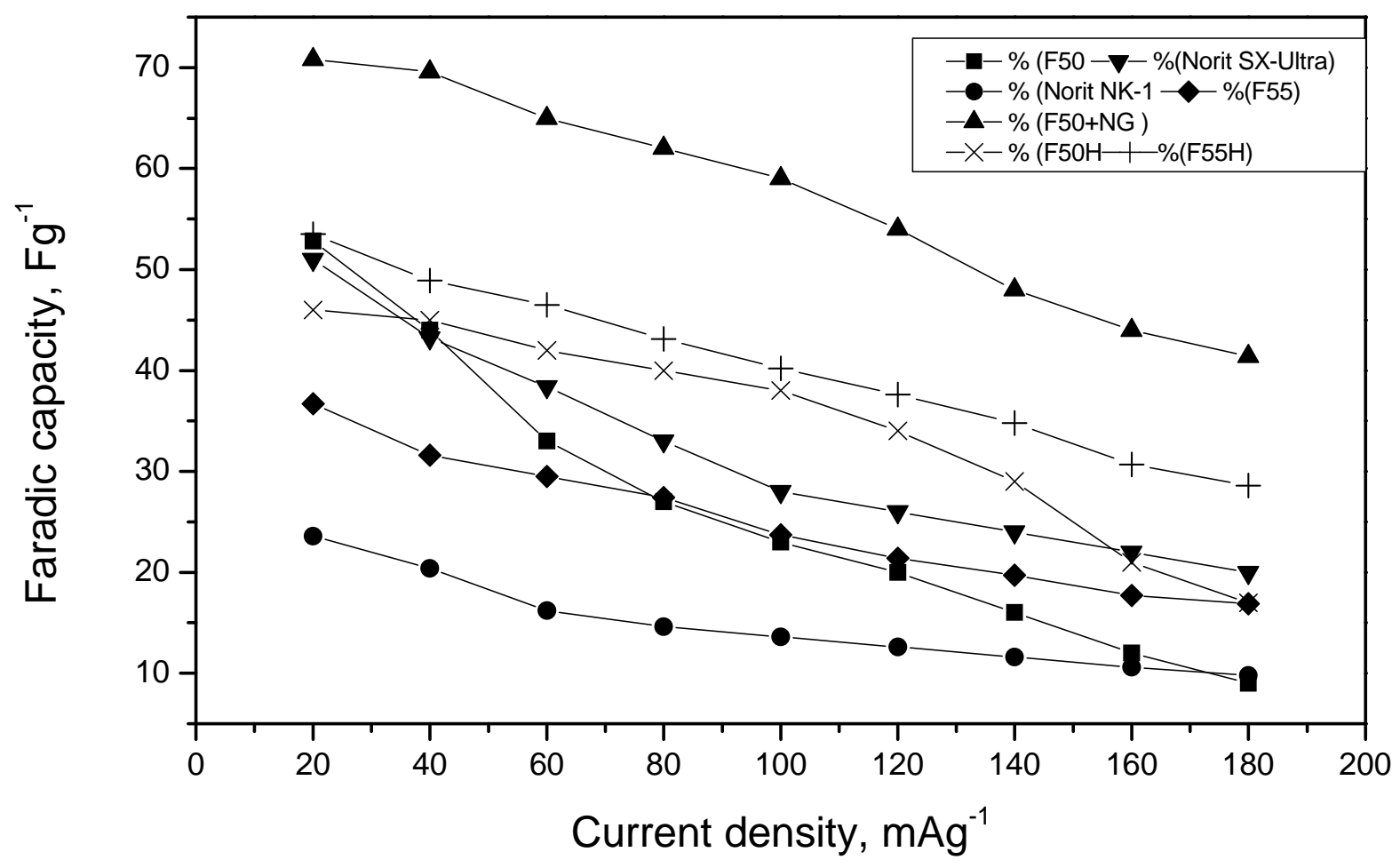

Figure 3. Dependence of the capacity from discharging current for capacitors with different carbon materials. 